University of Nebraska - Lincoln

DigitalCommons@University of Nebraska - Lincoln

\title{
Livestock Protection Dogs in the 21st Century: Is an Ancient Tool Relevant to Modern Conservation Challenges?
}

Thomas M. Gehring

Kurt C. VerCauteren

USDA-APHIS-Wildlife Services, kurt.c.vercauteren@usda.gov

Jean-Marc Landry

Follow this and additional works at: https://digitalcommons.unl.edu/icwdm_usdanwrc

Part of the Environmental Sciences Commons

Gehring, Thomas M.; VerCauteren, Kurt C.; and Landry, Jean-Marc, "Livestock Protection Dogs in the 21st Century: Is an Ancient Tool Relevant to Modern Conservation Challenges?" (2010). USDA Wildlife Services - Staff Publications. 919.

https://digitalcommons.unl.edu/icwdm_usdanwrc/919

This Article is brought to you for free and open access by the U.S. Department of Agriculture: Animal and Plant Health Inspection Service at DigitalCommons@University of Nebraska - Lincoln. It has been accepted for inclusion in USDA Wildlife Services - Staff Publications by an authorized administrator of DigitalCommons@University of Nebraska - Lincoln. 


\title{
Livestock Protection Dogs in the 21st Century: Is an Ancient Tool Relevant to Modern Conservation Challenges?
}

THOMAS M. GEHRING, KURT C. VerCAUTEREN, AND JEAN-MARC LANDRY

\begin{abstract}
Europe and North America share a similar history in the extirpation and subsequent recovery of large carnivore and ungulate species. Both continents face challenges and opportunities for managing human-wildlife conflict at the junction of livestock production and wildlife conservation. Predation of livestock and disease transmission between wildife and livestock is an ongoing and escalating worldwide issue. In order to manage this conflict, producers need effective tools, and they have used livestock protection dogs (LPDs) for reducing predation for well over 2000 years. We review the history of the use of LPDs, including the loss of information on their use and the paucity of scientific research on their effectiveness. We discuss the potential for LPDs to be integral components in modern-day livestock husbandry and outline future directions to pursue.
\end{abstract}

Keywords: disease, livestock protection dogs, predation, wildlife damage management

M any species of wildlife in Europe and North America have shared similar fates over the past 200 years. Overharvest and extirpation of some ungulate and large carnivore species characterize both continents, as do the destruction and development of habitats (Enserink and Vogel 2006). Over the last 30 years, however, some of these species have demonstrated remarkable resilience in their recovery in several regions of Europe and North America, either through natural recolonization or reintroduction programs.

The use of livestock protection (guarding) dogs (LPDs) appeared centuries ago throughout central Europe and Asia to help shepherds protect their goats and sheep from predators, namely brown bears (Ursus arctos) and gray wolves (Canis lupus; figure 1). With the eradication of many predators from the European landscape, the mass migration of humans to urban settings, and the collectivization agricultural policy under communist regimes, much of the knowledge of the use of LPDs was lost. In North America, European immigrants during the 1800s and 1900s did not bring knowledge of the use of LPDs, nor did they incorporate them into their farming practices, as evidenced by the relatively few producers actively using LPDs before the 1970s. Navajo Indians, though, did employ nonstandard LPDs for guarding livestock, presumably having learned the technique from early Spanish explorers (Lyman 1844, Dyk 1938, Black 1981, Black and Green 1985).
Past studies on LPDs, especially those with experimental rigor, are limited. Rigg (2001) presented a general overview of LPDs, and Coppinger and Coppinger (2001) provided a comprehensive review of LPD behavior and selection. Shivik (2006) briefly discussed LPDs in his review of nonlethal tools for managing predators. Smith and colleagues (2000) reviewed the use of guardian animals and focused most of their review on LPDs. All of these reviews have focused rather narrowly on using LPDs for deterring predation on livestock (principally sheep). Our intent is to provide a rigorous, updated overview of the current use of LPDs for protecting livestock from predation and to discuss the potential for using LPDs to reduce disease transmission from wildlife to livestock, as well as for conserving wildlife populations. We provide an overview of the similarities between European and North American livestock production, wildlife conflict, and wildlife conservation. On both continents, society has come to value wild ungulates and large carnivores and to prefer the use of nonlethal management tools for addressing conflicts. We outline the need for effective, nonlethal, producer-based tools to allow producers to manage these conflicts themselves. Livestock protection dogs may also offer a proactive and "green" tool for allowing livestock husbandry and wildlife to coexist (i.e., a unique conservation value). We review the history of the use of 

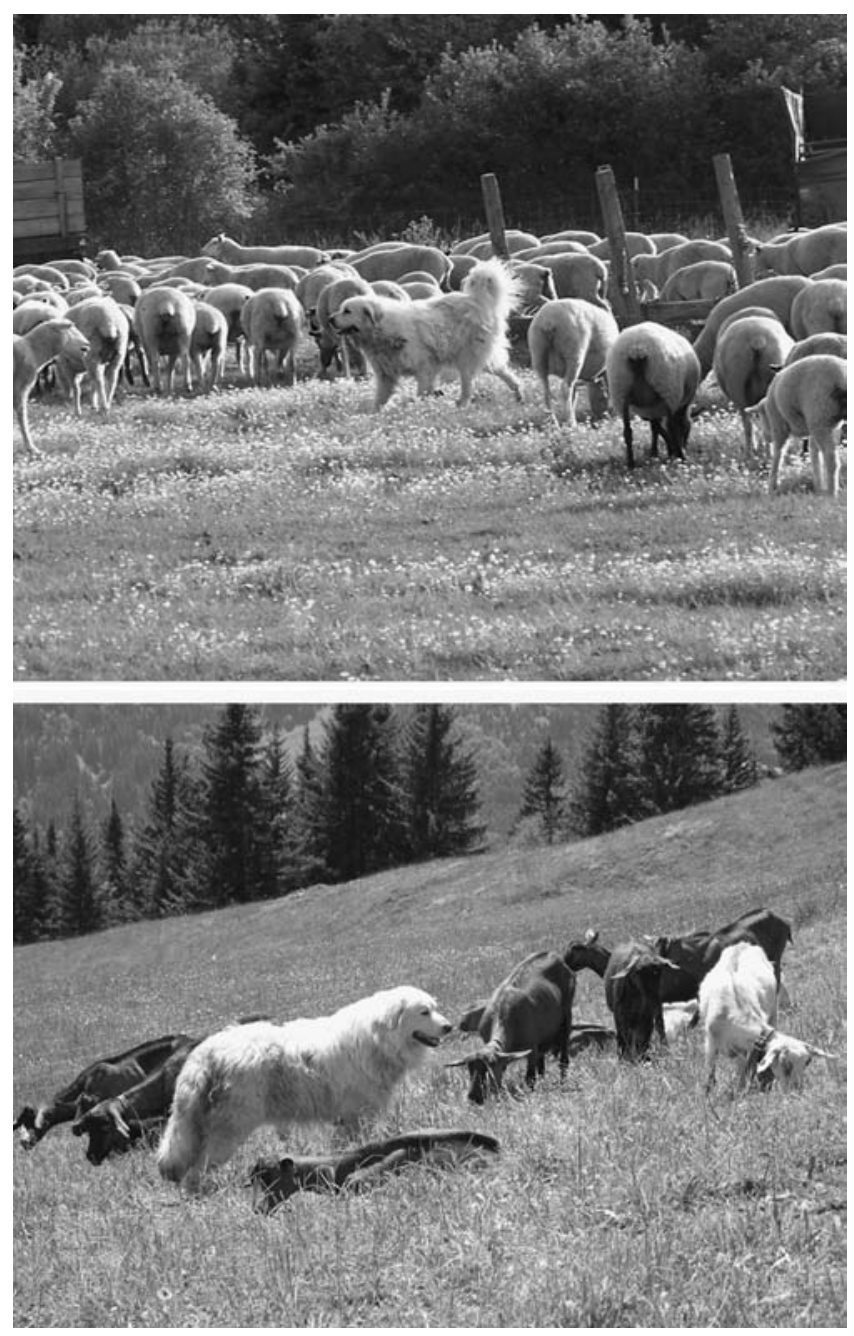

Figure 1. Livestock protection dogs were developed in Asia and Europe to protect sheep and goats from brown bears and gray wolves. Photograph: Thomas M. Gehring and Kurt C. VerCauteren.

LPDs, including the lull in their use following the eradication of wolves in Europe and North America and the paucity of scientific research on their effectiveness. Further, we outline future directions to pursue and the potential for greater conservation value through the use of LPDs.

\section{Similarities between Europe and North America}

Producers in Europe and North America are confronted with similar challenges in their efforts to reduce livestock losses to predators and wildlife-transmitted diseases, while doing their part to facilitate human coexistence with wildlife. This is especially true in areas where wolves have recently recovered (e.g., the western Great Lakes region of the United States) or are actively recolonizing (e.g., the western part of the Alps range in Europe, the northern US Rocky Mountains). Effective on-farm methods are needed to reduce deer activity near livestock in order to minimize the transmission, both directly and indirectly, of diseases such as bovine tuberculosis (TB) from infected deer (Odocoileus spp.) to livestock (VerCauteren et al. 2008). Other wildlife-transmitted diseases of livestock include brucellosis, keratoconjunctivitis, and neosporosis. Producers in these regions require efficacious tools that they can adapt into their normal husbandry practices in order to reduce economic losses.

In the past, lethal control tools (e.g., trapping, shooting) were used extensively to remove predators from areas (e.g., bounty system). Government-funded lethal removal continues to be the primary management tool used in recovered wolf populations in North America within the conflictmanagement model of reactionary management (i.e., lethal removal after depredation occurs; Musiani et al. 2005). However, lethal methods alone have not eliminated wolf depredations. Musiani and colleagues (2005) reported that lethal control of wolves in Alberta, Canada (applied as reactionary management on individual farms), did not reduce the number of livestock depredations at a regional level. In Spain and Canada, although wolves are hunted, livestock depredation continues to occur and is an important issue. In the case of recovering wolf populations, lethal control may remain a last resort because the goal of current management in many areas is to increase populations to predetermined target levels. Even in areas where wolf populations have surpassed target levels for recovery, the legal challenges to delisting the populations may limit the use of lethal control (e.g., in the western United States and Great Lakes region). Unregulated lethal-control and market-hunting (e.g., unregulated hunting of wildlife for sale in markets) policies played a major role in reducing or eliminating many carnivore and ungulate populations in the 19th century in North America and Europe (Trefethen 1961, Landry 2001). Such practices are no longer legally or socially acceptable for managing these conflict issues. Currently, nonlethal control methods are more acceptable to the public than regulated lethal options in both Europe and North America (Reiter et al. 1999, Breitenmoser et al. 2005). However, many of the costs associated with nonlethal management tools are borne by producers.

Current governmental management objectives and laws have relegated producers on both continents to passive and reactionary roles in the management of livestock depredations (Gehring and Potter 2005). In such positions, producers often become overly reliant on government agencies or may fail to become proactive in managing human-wildlife conflict on their property (Gehring et al. 2006, O'Brien et al. 2006). The integration of LPDs might give producers another opportunity to become active managers in protecting their livestock, helping them become integrated and active stakeholders in the wider management process (Gehring and Potter 2005). By employing LPDs, a nonlethal method, producers would also aid the conservation of large predators.

The use of LPDs by livestock producers in Europe and North America is primarily an economic and political issue. In Europe, large carnivores are protected by the Bern Convention or local hunting laws. Sheep producers in areas of France and Switzerland where wolves are recolonizing receive government financial support to implement the use of LPDs. Thus, political mandates for large carnivore conservation have 
forced these producers to implement preventative measures to protect their livestock, and the use of LPDs has allowed wolves to live in these areas (e.g., Ribeiro and Petrucci-Fonseca 2004). Sheep producers in Spain (e.g., Castilla y Leon) have used LPDs for centuries, but still request government support for reducing wolf populations in some regions to reduce risk to their livestock. In North America and some regions of Europe (e.g., the northern part of Castilla y Leon), there is little to no governmental support for using LPDs; producers must bear most or all of the financial costs. Additionally, on both continents and worldwide, wildlife acts as a reservoir of diseases that may be transmitted to livestock. LPDs are beginning to be recognized for their ability to reduce this transmission of disease.

\section{History of use of livestock protection dogs}

The far-distant ancestor of LPDs is believed to be a predecessor of the modern-day mastiff that lived on the high Tibetan plateaus during prehistoric times (Guardamagna 1995). However, LPDs most likely originated in Mesopotamia and its peripheral regions, where livestock husbandry was well developed (Landry 1999). The first indications of the domestication of sheep (beginning with the Asiatic mouflon) and goats (starting with the bezoar goat) were found in western Asia (Iraq and Iran) dating back about 7000 or 8000 years BCE (Gauthier 1990). Domestic dogs and sheep appeared together for the first time in archaeological sites dated 3585 BCE (Olsen 1985). It is also likely that Sumerian nomadic shepherds already had dogs with their flocks to protect sheep and goats against predators, during the transhumance between Mesopotamia and the modern-day country of Hungary. In the Old Testament, Job mentions the presence of a dog with its flock (Job 30:1). Very large dogs existed in Assyria in the 13th century BCE, as can be seen in representations of dogs on various bas-reliefs and on terra-cotta from the ruins of Babylon or Niniveh. Chinese chronicles relate that such a dog was offered to the Chinese emperor in 1121 BCE (Guardamagna 1995). Moreover, Alexander the Great is reported to have received two dogs from an Indian king, which he brought back to Macedonia into the Molosses region in 326 BCE. Since then, these dogs have been given the name of molosses (Guardamagna 1995). The Romans used molosses for circus games, combat, and to guard villas and estates. A Roman farm-management treatise (published in 150 BCE) mentioned two types of dogs: One was used to hunt predators and game; the other was used to protect herds of livestock (cited in Coppinger and Coppinger 1993).

It is likely that early LPDs were simply dogs that were raised with and bonded to livestock, and thus available and adapted to the task. The first ancestors of LPDs then most likely spread from their native regions with nomadic tribes along different migration routes or with merchants. The diversity of LPDs originated from these exchanges (especially during the transhumance) and was a result of postzygotic selection (see Coppinger and Coppinger 2001 for a more complete discussion). Shepherds favored and cared for dogs that had morphological or behavioral characteristics that enabled them to outperform other dogs in pastoral tasks. These animals were not sexually isolated from the greater dog population until recent times, and even then, sexual isolation occurs mostly in the West as performed by dog breeding associations (Coppinger and Coppinger 2001). In Spain, shepherds crossbred the Mastín mastiff with village dogs because the purebred Mastín mastiff did not satisfactorily meet pastoral needs (e.g., it was too heavy to run after wolves). However, different projects also try to maintain or recover pastoral characteristics of local or national LPDs (e.g., Ribeiro and Petrucci-Fonseca 2005). Today, there are at least 40 "breeds" of LPDs throughout the world (Landry 1999). The use of LPDs in Europe has resurged as large predator species have recovered (Ribeiro and Petrucci-Fonseca 2004); for example, more than 1000 LPDs are now working in the Alps. In North America, the use of LPDs has been a relatively recent phenomenon, initiated only in the 1970s (Linhart et al. 1979). By 2004, 32\% of sheep producers were using LPDs to protect their livestock in the United States (NASS 2005), where LPDs are used principally to protect sheep from coyotes (Canis latrans).

Worldwide, there is some variation in how LPDs have been applied by producers relative to geography, the producer's husbandry practices, and grazing situations. For example, in Sweden and the Great Lakes region of the United States, LPDs are often used in fenced pastures (figure 2; Levin 2005, Gehring et al. 2006, VerCauteren et al. 2008).

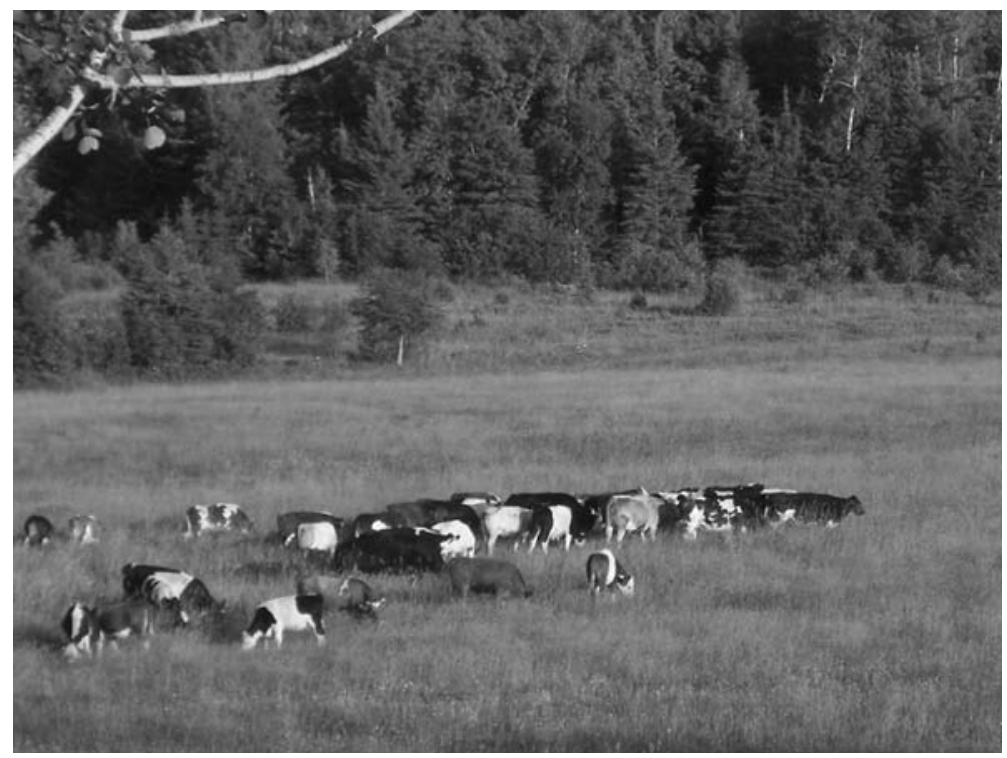

Figure 2. In the northern Great Lakes region of the United States, farm pastures are relatively small, confined grazing systems surrounded by forest. Livestock protection dogs can be fairly easily integrated into this type of grazing system. Photograph: Megan Provost. 
In these situations, LPDs are present with livestock on relatively small pastures ( $<50$ hectares) during summer months and then are brought closer to buildings during winter. LPDs accompany the livestock as they are rotated among pastures and even into barns. In remote and undeveloped regions of North America, Europe, and Asia, transhumances involve the movement of livestock to open range in high country during summer months and relocation back down to fenced pastures and barns during winter, as has been done for centuries. In southern regions of Europe (e.g., France), it is common for sheep to graze outside throughout the year, except during lambing season. In these cases, LPDs continually accompany livestock and shepherds (Lapeyronie et al. 2002).

\section{Studies of livestock protection dogs and predators}

Research on the effectiveness of using LPDs to deter predators from killing livestock has been largely on the basis of testimonial evidence (Linhart et al. 1979), producer-based reporting (Coppinger et al. 1988), limited captive trials (Linhart et al. 1979, McGrew and Blakesley 1982), and questionnaire surveys of producers (e.g., Andelt and Hopper 2000). Surveys often do not allow researchers to control for confounding factors (e.g., density of predators, vulnerability of livestock, livestock husbandry, variability among individual LPDs and breeds, experience of shepherds, other predator control programs), and producer-based counts of losses due to predators are often unreliable (Green and Woodruff 1983). Several studies have attempted to avoid some of these problems by relying on producers to rate their LPDs' effectiveness over successive years, controlling for LPDs that are too young, and comparing LPD-protected livestock to unprotected neighboring herds and flocks (e.g., Coppinger et al. 1988, Andelt 1992). However, many accounts of the effectiveness of LPDs in reducing livestock losses from predators are anecdotal and may lack objectivity (e.g., Gingold et al. 2009).

LPDs have successfully reduced predation, mainly from coyotes, on individual farms (Green et al. 1984, Coppinger et al. 1988, Andelt 1992). Most published accounts suggest that LPDs can reduce sheep depredation by $11 \%$ to $100 \%$ (see Smith et al. 2000). The vast majority of these studies pertain to sheep operations with coyotes as the primary predator. A variety of accounts suggest that LPDs may protect livestock from other predators, including caracals (Caracal caracal), cheetahs (Acinonyx jubatus), jackals (Canis mesomelas), leopards (Panthera pardus), baboons (Papio spp.; Rigg 2001), brown bears (Hansen and Smith 1999), and wolves (cited in Coppinger et al. 1988, Coppinger and Coppinger 1996, Ribeiro and Petrucci-Fonseca 2004, 2005), but little empirical evidence is provided. Though most studies have highlighted the use of LPDs with sheep operations, in the United States, France, and Switzerland we have recently integrated LPDs into cattle herds to guard against deer, coyotes, and wolves (Gehring et al. 2006, VerCauteren et al. 2008, Landry 2010). LPDs traditionally have been used to protect cattle in other parts of Europe and Asia (e.g., Turkey), although this practice is much less common compared with sheep protection. LPDs also are commonly used to protect goat flocks and less frequently to protect other social animals such as llamas, alpacas, and ostriches (Landry 1999).

Linhart and colleagues (1979) provided some of the first empirical evidence on the effectiveness of LPDs in field trials. On three sheep ranches, they found that the presence of LPDs reduced sheep depredations from coyotes over a 20-day period, and even for 20 days after dogs were removed-a possible residual effect of LPDs (i.e., possible displacement of coyotes from ranches; Linhart et al. 1979). Hansen and Smith (1999) reported that sheep depredations from brown bears in their two research flocks were lower compared with neighboring sheep flocks. They also observed that sheep depredations occurred 14 days earlier on flocks outside their study area, presumably due to the presence of LPDs in their study flocks. Hansen and Smith (1999) acknowledged that small sample sizes and study design could have been issues with their study (e.g., $30 \%$ to $50 \%$ of research flocks grazed outside their study area and LPDs were not integrated properly with sheep flocks). The Hansen and Smith (1999) study provided the first field evaluation of LPDs under different farm management systems (free-ranging LPDs with no supervision, freeranging LPDs with supervision by a shepherd, LPDs within a fenced pasture). Hansen and Smith (1999) suggested that the LPDs working within a fenced pasture were the most effective for reducing predation. However, Coppinger and colleagues (1988) and Green and Woodruff (1990) did not find a noticeable difference in the effectiveness of LPDs on open-range ranches compared with farms with fenced pastures. Coppinger and colleagues (1988) reported that LPDs were least effective when sheep were widely dispersed, not flocked, and where producers spent only minimal time monitoring flocks. Andelt and Hopper (2000) reported that LPDs appeared to be more effective at reducing sheep losses from black bears and mountain lions on open ranges compared with fenced pastures.

On the basis of producer-collected reports, Coppinger and colleagues (1988) found that LPDs reduced predation by $64 \%$, and in one year, $53 \%$ of producers with LPDs had depredation losses reduced to zero. Using questionnaire surveys, Andelt and Hopper (2000) reported that sheep producers in Colorado with LPDs lost fewer lambs to predators. In fact, producers without LPDs lost almost six times more lambs than producers with LPDs. Of the 160 producers surveyed, $84 \%$ reported that their LPDs were excellent or good at reducing predation on sheep. Andelt and Hopper (2000) reported an annual savings of $\$ 1149$ and $\$ 3610$ for producers using LPDs in fenced pasture and open range, respectively. Green and Woodruff (1988) conducted a survey of US and Canadian sheep and goat producers who employ LPDs. They found that $71 \%$ of producers rated LPDs as very effective against predation (Green and Woodruff 1988). Green and colleagues (1984) conducted a cost-benefit analysis of LPDs for predator control, primarily coyotes, for 70 sheep and 
goat operations in 16 states and 2 Canadian provinces. They found that $89 \%$ of producers valued LPDs as an economic asset. The annual savings experienced with using LPDs was between $\$ 180$ and $\$ 14,487$ (Green et al. 1984). Our questionnaire survey of cattle and sheep producers in Michigan suggested that perceived risk of livestock depredation was too low to warrant the use of LPDs, and producers believed LPDs would not be effective.

There is a dearth of experimental research on the effectiveness of LPDs, especially against wolf predation of livestock. This might be explained by the fact that wolf recovery in the United States and elsewhere is relatively recent. There is only one published account of LPD-wolf interactions; albeit this study had a very low sample size (cited in Coppinger et al. 1988, Coppinger and Coppinger 1996). These researchers found that LPDs displayed protective behaviors against wolves (as dominance ritualistic behavior) without injury to dogs or wolves. They also reported that LPDs were capable (in most cases) of defending experimenter-created food-cache stations from wolves and black bears (Ursus americanus) in Minnesota. However, this study was based on only one or two LPDs, and the researchers did not make direct observations of LPD behavior in defending the bait stations. Using producer-based interviews, Ribeiro and Petrucci-Fonseca (2004) observed a 33\% to $100 \%$ reduction in wolf-caused depredations on farms with LPDs, compared with the average rate of depredation before integrating LPDs. Ribeiro and Petrucci-Fonseca (2005) found that 75\% of producers reported a decrease in depredations after integrating LPDs.

We have conducted preliminary studies on the effectiveness of LPDs for excluding mesopredators (e.g., foxes, raccoons, skunks) from pastures. Our results suggest that LPDs are effective in excluding these predators, with fewer mesopredator visits into pastures compared with control farms. Exclusion of mesopredators from pasture systems might reduce rates of nest predation for ground-nesting birds in pastures protected by LPDs. Our control pastures had fewer ground-nesting bird nests and greater rates of predation compared with LPD-protected pastures. Similarly, we found lower numbers of small mammals (e.g., deer mice, Peromyscus maniculatus and meadow voles, Microtus pennsylvanicus) present in pastures containing cattle protected by LPDs. Hansen and Smith (1999) noted that LPDs attacked and killed approximately $50 \%$ of marmots (Marmota spp.) that they encountered.

\section{Studies of livestock protection dogs and ungulate diseases}

Researchers have recently begun to apply dogs to other wildlife damage management scenarios. For example, researchers have demonstrated that dogs (e.g., huskies) were useful for reducing deer damage to valued resources such as forest plantations, orchards, and organic vegetable farms (e.g., VerCauteren et al. 2005). Others have demonstrated the utility of dogs (e.g., border collies) for keeping nuisance geese away from golf courses and similar areas (e.g., Castelli and Sleggs 2000). Hansen and Smith (1999) reported that $85 \%$ of encounters between LPDs and wildlife resulted in the LPDs either chasing or following the wildlife species, including moose (Alces alces) and roe deer (Capreolus capreolus).

VerCauteren and colleagues (2008) were the first to evaluate and subsequently demonstrate the value of traditional LPDs for deterring potentially infectious deer from livestock areas. Evidence that the approach had potential to mitigate losses was found in other studies where dogs were anecdotally documented to pursue deer and reindeer (Rangifer tarandus; Coppinger et al. 1988, Hansen and Bakken 1999). Gingold and colleagues (2009) reported that mountain gazelles (Gazella gazella) found in LPD-protected cattle enclosures were more vigilant, spent more time running and less time resting and walking, and avoided cattle herds as compared with gazelles in enclosures without LPDs. Further, they found that LPDs had a negative effect on a valued wildlife species by reducing gazelle reproductive success by preying upon gazelle fawns. Similar to our findings concerning predation, our questionnaire survey of producers in Michigan suggested that perceived risk of disease transmission was too low to warrant the use of LPDs, and producers believed LPDs would not be effective.

The VerCauteren and colleagues (2008) study showed LPDs to be a valuable and cost-effective asset in reducing deer contact with livestock, consumption of feed intended for livestock, and use of cattle pastures. The use of LPDs also might be a valuable tool for deterring other infectious ungulates from approaching livestock. In the western United States, for example, LPDs might be integrated with cattle to prevent elk (Cervus elaphus) and bison (Bison bison) that are potentially infected with brucellosis from interacting with cattle. Also, dogs may be a useful, nonlethal means of limiting disease transmission to cattle from species such as tuberculosis-infected badgers (Meles meles) and brushtail possums (Trichosurus vulpecula) in the United Kingdom and New Zealand, respectively. LPDs might be also regarded as a new management tool in the Alps to reduce the transmission of infectious keratoconjunctivitis (causative agent, Mycoplasma conjunctivae) among sheep, chamois (Rupicapra rupicapra), and ibex (Capra ibex), although the transmission mode is not clearly understood. However, consideration of diseases that LPDs might introduce or perpetuate (e.g., neosporosis; Gondim et al. 2004) must also be considered and preventative actions taken.

\section{Are LPDs the best tool?}

In his review, Shivik (2006) briefly discussed the use of LPDs among several other nonlethal management tools for mitigating human-predator conflict. He defined two major types of management tools that managers might use to repel predators from preying upon livestock: (1) disruptive-stimulus tools, or primary repellents, which disrupt and frighten predators from a site without long-term modification of behavior; and (2) aversive-stimulus tools, or secondary 
repellents, which ultimately modify predator behavior through operant or free-operant conditioning. Moreover, Shivik (2006) identified LPDs as possibly the "ultimate disruptive-stimulus tool." Our LPD research supports the opinion that LPDs are excellent disruptive-stimulus tools, and we further suggest that LPDs may be an aversivestimulus tool that can cause predators and ungulates to modify their behavior (e.g., shift their spatial use or time spent in an area due to the presence of a perceived threat). For example, producers in our studies provided numerous anecdotal accounts of deer no longer using pastures once LPDs were placed there. Additionally, the study by Gingold and colleagues (2009) documented modified behaviors (including avoidance of cattle herds) among gazelles in LPDprotected enclosures. This mechanism may be reinforced by the indirect (e.g., barking, scent-marking) and direct (e.g., pursuit) physical harassment that LPDs exert on predators and ungulates. However, barking and scent marking by LPDs may attract wolves. There are also cases wherein the barks of LPDs may not intimidate predators such as coyotes (Linhart et al. 1979) or wolves, which may then challenge some of the more cowardly LPDs (McGrew and Blakesley 1982). Several interactions between wolves and LPDs (recorded using a thermal camera) in Parc national du Mercantour, France, strongly suggested that wolves were not frightened by the presence of LPDs. We observed one or two wolves remaining on the same alpine pasture for 10 hours and interacting with LPDs a minimum of 15 times. This suggests a role of LPDs is to disrupt the predatory actions of wolves.

Shivik (2006) also provided three measures (biological efficiency, economic efficiency, and psychological assuagement) as a rubric for determining the effectiveness of nonlethal tools. From an effectiveness standpoint, LPDs appear to provide (a) high biological efficiency due to possible application of LPDs for protecting multiple livestock species from various threats (e.g., disease and predation) posed by different species of wildlife; (b) high economic efficiency, as using dogs is relatively low cost (e.g., $\$ 850$ per year in the United States, VerCauteren et al. 2008; $\$ 906$ per year in Switzerland, Landry et al. 2005) once dogs are trained, and relatively low maintenance after initial time and cost investment; and (c) psychological peace of mind and lower stress among producers that have LPDs protecting their flocks and herds (i.e., LPDs are a partner and companion in the producer's operation and work 24 hours per day, 7 days a week; figure 3). Producers involved in our studies have provided anecdotal evidence of lowered stress when LPDs were working on their farms. We suggest LPDs have the potential to be an effective nonlethal management tool as a result of their flexibility and versatility in applications to multiple livestock types and conflict issues with a variety of wildlife species. Additionally, LPDs could be used proactively before depredations occur rather than in the typical conflictmanagement model of reactionary management (i.e., on a case-by-case basis after a problem arises). For producers, LPDs are effective both economically and psychologically when accounting for initial investment costs, maintenance costs, durability, generality, time and labor, independence from reliance on electronics and other advanced technology (e.g., radio-activated guard boxes and associated costs; Breck et al. 2002, Shivik 2006), and independence from reliance on logistical support from government agencies (table 1).

However, LPDs alone may not always completely prevent predation or wildlife damage, so an integrated management strategy that employs a variety of nonlethal and lethal management tools is recommended. In the Alps, it was shown that LPDs work best together with night penning and the presence of a shepherd (Espuno et al. 2004). LPDs also could
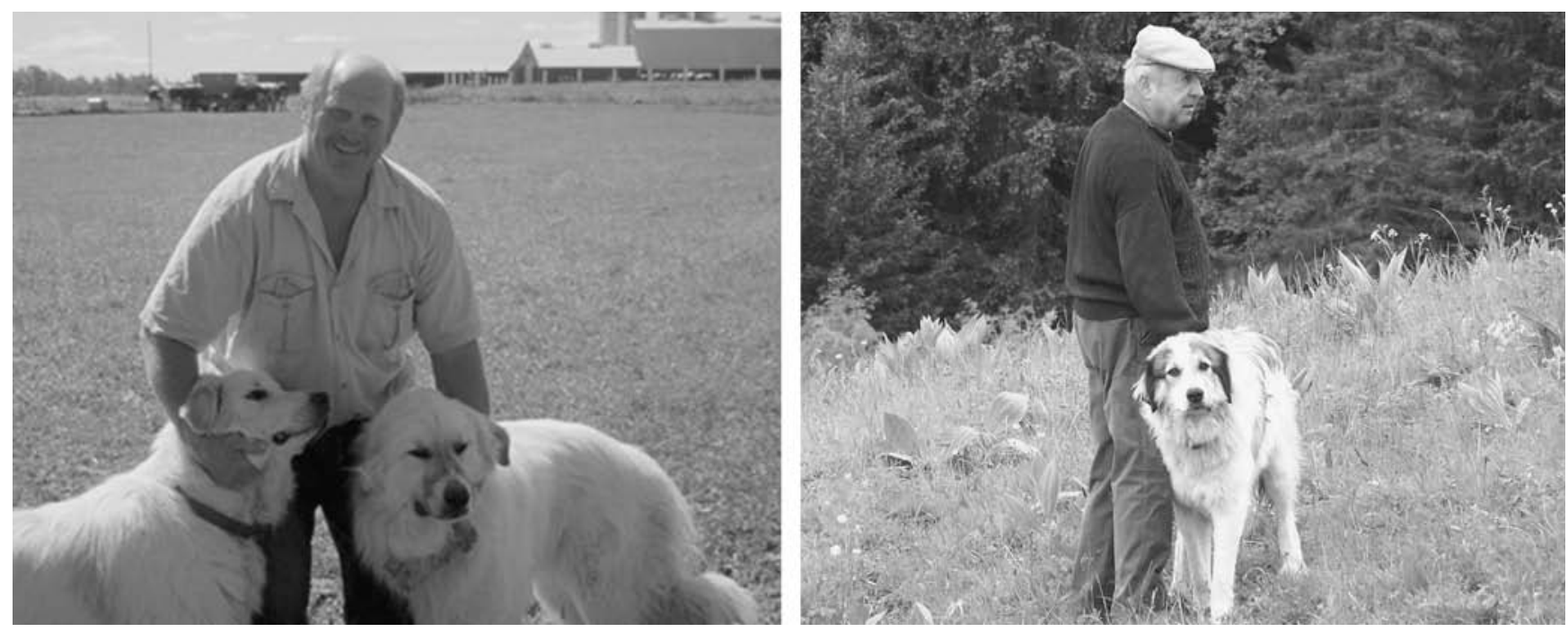

Figure 3. Livestock protection dogs (LPDs) are partners and companions in a producer's operation. The ability of LPDs to monitor pastures continuously can lead to psychological peace of mind and lower stress for producers. Photographs: Megan Provost and Thomas M. Gehring. 


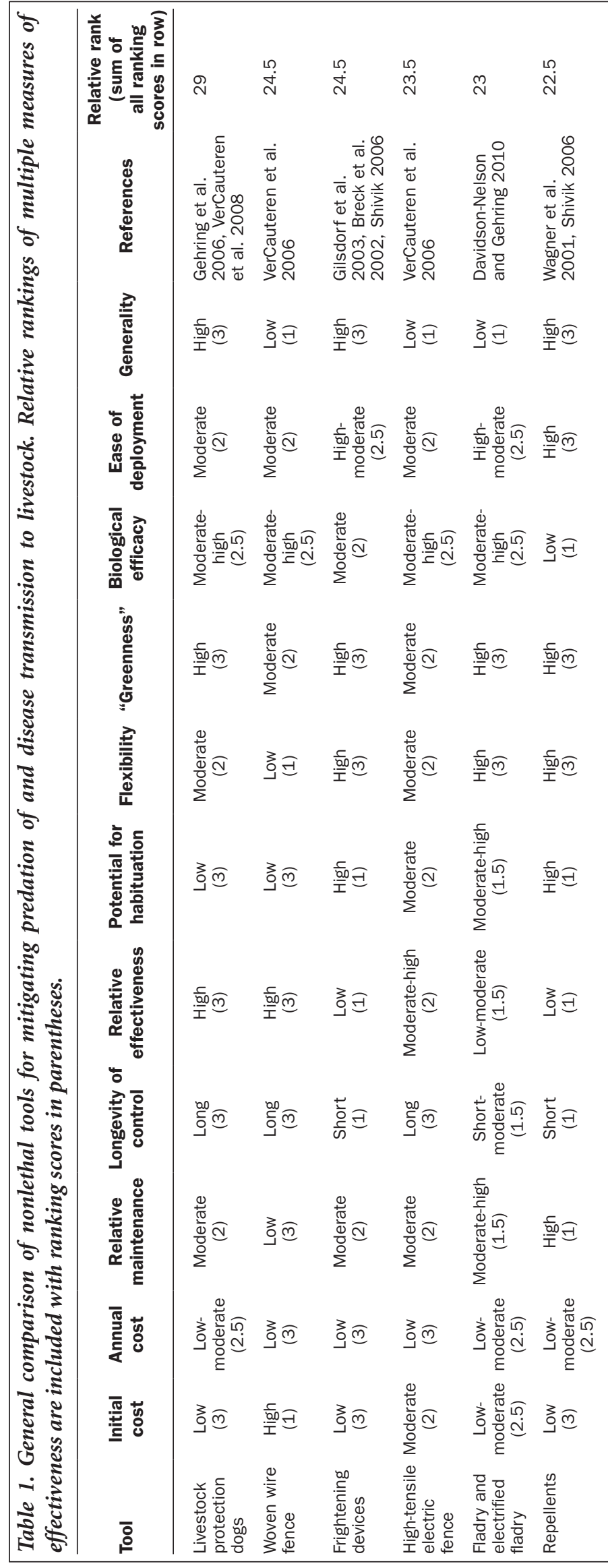

lead to additional negative costs to producers (e.g., killing livestock; wandering and harassing people; or being killed by vehicles, poisoning, or shooting). However, careful selection of the appropriate breed and individual pups, proper assimilation into the livestock herd or flock, and removal of undesirable individuals can help reduce LPD problems (figure 4). The use of LPDs is not necessarily adaptable to all situations, especially in areas (e.g., Jura Mountains, France) where producers keep their cattle in several small herds near each other. The number of LPDs required to individually protect each herd may reach an unmanageable amount of dogs (e.g., thousands within a 5000-square-kilometer area). In these cases, other preventive tools (e.g., electrified fences) might be preferred. Moreover, the handling of LPDs in cattle herds can be more difficult compared with sheep flocks. Another important factor to consider is the proximity of LPDs to human disturbance. In the Alps, where transhumance is common, the management of LPDs can become problematic during winter, especially close to urban zones or villages. In these circumstances of close confinement, LPDs may become inattentive and begin to wander, chase vehicles, harass people, or bark during the night, resulting in increased conflicts with neighbors. As a result, some local authorities forbid LPDs within their communities or cancel rental agreements for communal fields.

Historically, there has been a shortage of information on how often LPDs failed to prevent losses to wolf depredation, and beyond that, whether wolves occasionally killed LPDs. In the wolf-recovery area of the western United States, wolves have recently killed LPDs (Bangs et al. 2005). Personnel from the US Department of Agriculture Wildlife Service have documented multiple instances in recent years when packs of wolves killed or injured LPDs. Mertens and Schneider (2005) reported on one area of Romania where LPDs were regularly attacked and killed by wolves, even near homes, but usually in remote areas and close to forests. In France, a few LPDs have recently been killed or injured by wolves. Although these kinds of events appear uncommon, wildlife managers suspect that encounters and fights between LPDs and wolves may be on the rise. In instances where specific wolf packs learn to kill LPDs, more drastic, and most likely lethal, control measures may be warranted. Wolves probably regard some LPDs as conspecifics and exhibit territorial behavior against them. Specific factors that define why wolves sometimes attack or kill LPDs have not been determined.

\section{Future directions}

On the basis of our literature review and our research, we believe LPDs may be a valuable tool for protecting livestock and conserving valued wildlife in the 21st century and beyond. Presumably, the development and continued use of LPDs by early pastoralists for 

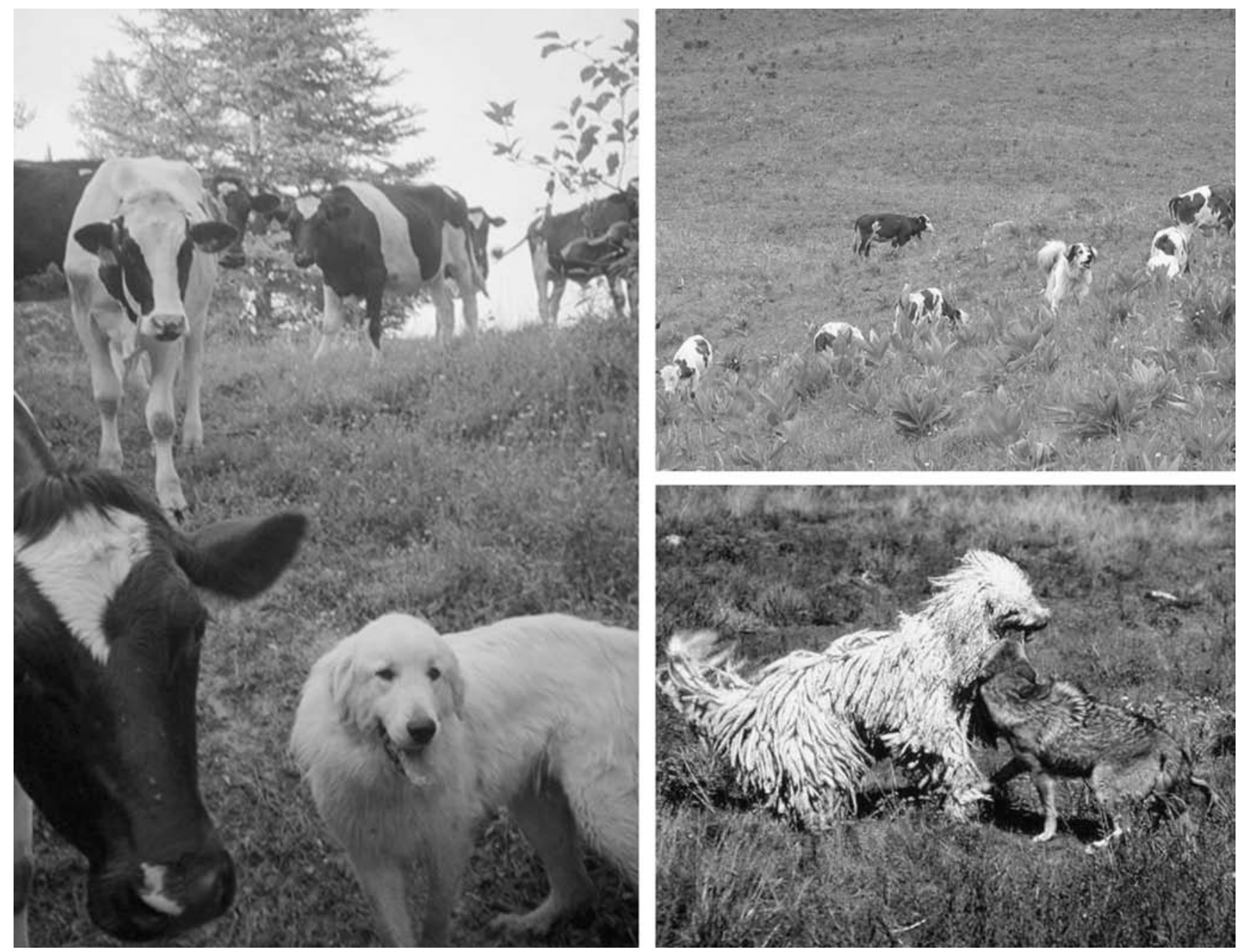

Figure 4. Effective livestock protection dogs display trustworthy, attentive, and protective behaviors. Photographs: Anna C. Cellar, Kurt C. VerCauteren, and the US Department of Agriculture Wildlife Service.

protecting sheep and goats signify the approach's apparent effectiveness. Past reviews (e.g., Smith et al. 2000) and our research suggest that LPDs are established as effective protectors of sheep from coyotes. The broad application of LPDs for protecting livestock (including cattle) from wolves or wildlife-transmitted disease is much more tenuous and is a rich area for additional research. More rigorous research is needed to definitively assess the effectiveness of LPDs in preventing livestock depredations from wolves or reducing the risk of livestock contracting zoonotic diseases. Past studies of LPDs have been based mostly on surveys of producer attitudes relative to the effectiveness of dogs for reducing predation. Although these data are valuable, there remains a need for more science-based studies of the effectiveness of LPDs, sensu using a large-scale experimental design (Breck 2004). The few field studies that have tested the effectiveness of LPDs have had either small sample sizes or no true control (e.g., as in a before-after-control-impact design). In order for LPDs to be recommended more extensively by managers as a nonlethal management tool for reducing livestock losses due to predators (especially wolves) or wildlife diseases, we require stronger proof of their effectiveness. Only then can the use of LPDs as a management tool be compared legitimately with other human-wildlife conflictmitigation techniques.

Only recently have researchers begun using experimental field approaches with LPDs (Gehring et al. 2006, VerCauteren et al. 2008, Gingold et al. 2009, Landry 2009). These recent studies suggest that LPDs may hold greater conservation value than has been realized in the past, though Hansen and Bakken (1999), Hansen and Smith (1999), and Gingold and colleagues (2009) documented possible negative impacts of LPDs on valued wildlife. Recent instances where LPDs have been used to protect cattle, reduce deer use of pastures, and prevent nest predators from accessing pastures demonstrate some of the potential novelty and versatility of this tool for addressing modern conservation challenges. We suggest that many additional applications of LPDs to various breeds of livestock and diverse species of carnivores and ungulates are still largely unexplored (e.g., Gingold et al. 2009). Research is needed to develop guidelines for use of LPDs with livestock on open ranges (e.g., western United States) or on small 
alpine pastures (e.g. Switzerland) in cases when a shepherd is not present.

Additional research is warranted to explore how the behavior of LPDs may correlate to their effectiveness for protecting livestock. Past studies have suggested that more aggressive LPDs might be more effective at deterring predation by bears, mountain lions, and wolves (Green and Woodruff 1989, 1990). However, aggressive LPDs might be more prone to kill small predators or domestic dogs, injure or kill livestock, and bite people (Green and Woodruff 1990). Thus, aggressive traits in LPDs might conflict with other human-use issues (e.g., recreation and tourist areas in the Alps and US Rocky Mountains). This conflict could become a political issue and result in the banning of LPDs in certain areas. Thus, we need further research on whether LPDs need to be aggressive in order to be effectual against large predators. Additional research is needed to gain a better understanding of why LPDs are sometimes killed by wolves, how the number of dogs in use might relate to this, and whether LPDs attract wolves.

We also need additional direct study of the economics of using LPDs. These studies might include more refined costbenefit modeling to assess producer risk and the conservation value of LPDs. New predator- and wildlife-friendly markets of livestock products may provide greater economic incentives for producers to use LPDs and other nonlethal management tools. Additional work should pursue forming producer exchange programs at local, regional, national, and international levels to discuss the use of LPDs in normal livestock husbandry. In particular, information exchanges between those producers who already use LPDs and those who do not in Europe and North America could lead to the development of a program for research, education, and outreach that would further address the modern conservation challenges of protecting livestock and conserving valued wildlife.

\section{Acknowledgments}

We thank Central Michigan University; the US Department of Agriculture Animal and Plant Health Inspection Service Wildlife Service, National Wildlife Research Center; Swiss Federal Office for the Environment; French Ministry of Agriculture; regional representatives of Switzerland and France in the Alps (Swiss Association for the Development of Agriculture and Rural Areas, Department of Agriculture and Forestry); Animal Welfare Institute (Christine Stevens Wildlife Award); CITGO Petroleum, Inc.; Defenders of Wildlife; and National Geographic Society Conservation Trust for support of our research on LPDs. We are grateful to Stewart Breck, Ray Coppinger, Jeffrey Green, Robert Woodruff, and three anonymous reviewers for constructive comments that improved this manuscript.

\section{References cited}

Andelt WF. 1992. Effectiveness of livestock guarding dogs for reducing predation on domestic sheep. Wildlife Society Bulletin 20: 55-62.

Andelt WF, Hopper SN. 2000. Livestock guard dogs reduce predation on domestic sheep in Colorado. Journal of Range Management 53: 259-267.
Bangs E, et al. 2005. Livestock guarding dogs and wolves in the northern Rocky Mountains of the United States. Carnivore Damage Prevention News 8: 32-39.

Black HL. 1981. Navajo sheep and goat guarding dogs: A New World solution to the coyote problem. Rangelands 3: 235-237.

Black HL, Green JS. 1985. Navajo use of mixed-breed dogs for management of predators. Journal of Range Management 38: 11-15.

Breck SW. 2004. Minimizing carnivore-livestock conflict: The importance and process of research in the search for coexistence. Pages 132-137 in Fascione N, Delach A, Smith ME, eds. People and Predators: From Conflict to Coexistence. Island Press.

Breck SW, Williamson R, Niemeyer C, Shivik JA. 2002. Non-lethal radio activated guard for deterring wolf depredation in Idaho: Summary and call for research. Pages 223-226 in Timm RM, Schmidt RH, eds. Proceedings of the 20th Vertebrate Pest Conference. University of California.

Breitenmoser U, Angst C, Landry JM, Breitenmoser-Würsten C, Linnell JDC, Weber JM. 2005. Non-lethal techniques for reducing depredation. Pages 49-71 in Woodroffe R, Thirgood S, Rabinowitz A, eds. People and Wildlife: Conflict or Coexistence? Cambridge University Press.

Castelli PM, Sleggs SE. 2000. Efficacy of border collies to control nuisance Canada geese. Wildlife Society Bulletin 28: 385-392.

Coppinger L, Coppinger R. 1993. Dogs for herding and guarding livestock. Pages 179-196 in Grandin T, ed. Livestock Handling and Transport. CAB International.

. 1996. Interactions between livestock guarding dogs and wolves. Pages 523-526 in Carbyn LN, Fritss SH, Seip DR, eds. Ecology and Conservation of Wolves in a Changing World. Canadian Circumpolar Institute, University of Alberta.

2001. Dogs: A Startling New Understanding of Canine Origin, Behavior and Evolution. Scribner.

Coppinger R, Coppinger L, Langeloh G, Gettler L, Lorenz J. 1988. A decade of use of livestock guarding dogs. Pages 209-214 in Crabb AC, Marsh RE, eds. Proceedings of the Thirteenth Vertebrate Pest Conference. University of Nebraska.

Davidson-Nelson SJ, Gehring TM. 2010. Testing fladry as a non-lethal management tool for wolves and coyotes in Michigan. Human-wildlife Interactions. Forthcoming.

Dyk W. 1938. Son of Old Man Hat: A Navajo Autobiography Recorded by Walter Dyk. University of Nebraska Press.

Enserink M, Vogel G. 2006. Wildlife conservation: The carnivore comeback. Science 314: 746-749.

Espuno N, Lequette B, Poulle ML, Migot P, Lebreton JD. 2004. Heterogeneous response to preventive sheep husbandry during wolf recolonization of the French Alps. Wildlife Society Bulletin 32: 1195-1208.

Gauthier A. 1990. La domestication. Et l'homme créa l'animal. Jardin des Hesperides. Errance ed.

Gehring TM, Potter BA. 2005. Wolf habitat analysis in Michigan: An example of the need for proactive land management for carnivore species. Wildlife Society Bulletin 33: 1237-1244.

Gehring TM, Hawley JE, Davidson SJ, Rossler ST, Cellar AC, Schultz RN, Wydeven AP, VerCauteren KC. 2006. Are viable non-lethal management tools available for reducing wolf-human conflict? Preliminary results from field experiments. Pages 2-6 in Timm RM, O'Brien JM, eds. Proceedings of the 22nd Vertebrate Pest Conference. University of California.

Gilsdorf J, Hygnstrom SE, VerCauteren KC. 2003. Use of frightening devices in wildlife damage management. Integrated Pest Management Reviews 7: 29-45.

Gingold G, Yom-Tov Y, Kronfeld-Schor N, Geffen E. 2009. Effect of guard dogs on the behavior and reproduction of gazelles in cattle enclosures on the Golan Heights. Animal Conservation 12: 155-162.

Gondim LFP, McAllister MM, Mateus-Pinilla NE, Pitt WC, Mech LD, Nelson ME. 2004. Transmission of Neospora caninum between wild and domestic animals. Journal of Parasitology 90: 1361-1365.

Green JS, Woodruff RA. 1983. The use of three breeds of dogs to protect rangeland sheep from predators. Applied Animal Ethology 11: $141-161$. 
1988. Breed comparisons and characteristics of use of livestock guarding dogs. Journal of Range Management 41: 249-250.

- 1989. Livestock-guarding dogs reduce depredation by bears. Pages 49-53 in Bromley M, ed. Bear-people Conflicts: Proceedings of a Symposium on Management Strategies. Northwest Territories Department of Renewable Resources.

- 1990. ADC guarding dog program update: A focus on managing dogs. Pages 233-236 in Lewis R, Marsh RE, eds. Proceedings of the 14th Vertebrate Pest Conference. University of California.

Green JS, Woodruff RA, Tueller TT. 1984. Livestock-guarding dogs for predator control: Costs, benefits, and practicality. Wildlife Society Bulletin 12: 44-50.

Guardamagna A. 1995. Le chien de Montagne des Pyrénées. de Vecchi.

Hansen I, Bakken M. 1999. Livestock-guarding dogs in Norway, part I: Interactions. Journal of Range Management 52: 2-6.

Hansen I, Smith ME. 1999. Livestock-guarding dogs in Norway, part II: Different working regimes. Journal of Range Management 52: 312-316.

Landry JM. 1999. The Use of Guard Dogs in the Swiss Alps: A First Analysis. KORA Report no. 2. (7 February 2010; www.kora.ch/pdf/reports/rep2_e. pdf)

2001. Le loup. Les sentiers du naturaliste. Delachaux et Niestlé.

. 2009. Test de comportement afin d'évaluer l'agressivité d'un chien de protection face à l'humain. Développement du test. IPRA Report no. 4. (1 February 2010; www.canis-ovis.com)

- 2010. Introduction et gestion de chiens de protection dans des troupeaux bovins. Premiers résultats. IPRA Report no. 5. (1 February 2010; www.canis-ovis.com)

Landry JM, Burri A, Torriani D, Angst C. 2005. Livestock guarding dogs: A new experience for Switzerland. Carnivore Damage Prevention News 8: 40-48.

Lapeyronie P, Olivier L, Molénat G. 2002. Fonctions de l'l'élevage dans la protection de l'environnement en montagne. Pages 197-212 in Transhumance Actes des journées Euro-méditerranéennes de la transhumance Relique du passé ou pratique d'avenir? Etat des lieux d'un savoir-faire euro-méditerranéen en devenir. Maison de la Transhumance. Cheminements. (12 March 2010; www.transhumance.org)

Levin M. 2005. Livestock guarding dogs in Sweden: A preliminary report. Carnivore Damage Prevention News 8: 8-9.

Linhart SB, Sterner RT, Carrigan TS, Henne DR. 1979. Komondor guard dogs reduce sheep losses to coyotes: a preliminary evaluation. Journal of Range Management 32: 238-241.

Lyman JH. 1844. Shepherd dogs. The American Agriculturist 3: 241-242.

McGrew JC, Blakesley CS. 1982. How Komondor dogs reduce sheep losses to coyotes. Journal of Range Management 35: 693-696.

Mertens A, Schneider H. 2005. What is wrong with Romanian livestock guarding dogs? A discussion. Carnivore Damage Prevention News 9: 9-14.

Musiani MT, Muhly T, Gates CC, Callaghan C, Smith ME, Tosoni E. 2005. Seasonality and reoccurrence of depredation and wolf control in western North America. Wildlife Society Bulletin 33: 876-887.
[NASS] National Agricultural Statistics Service. 2005. Sheep and Goats Death Loss. US Department of Agriculture National Agricultural Statistics Service. Report Mt An 2 (5-05).

O’Brien DJ, Schmitt SM, Fitzgerald SD, Berry DE, Hickling GJ. 2006. Managing the wildlife reservoir of Mycobacterium bovis: The Michigan, USA, experience. Veterinary Microbiology 112: 313-323.

Olsen JW. 1985. Prehistoric dogs in mainland East Asia. Pages 47-70 in Olsen SJ, ed. Origins of the Domestic Dog: The Fossil Record. University of Arizona Press.

Reiter DK, Brunson MW, Schmidt RH. 1999. Public attitudes toward wildlife damage management and policy. Wildlife Society Bulletin 27: 746-758.

Ribeiro S, Petrucci-Fonseca F. 2004. Recovering the use of livestock guarding dogs in Portugal: Results of a long-term action. Carnivore Damage Prevention News 7: 2-5.

- 2005. The use of livestock guarding dogs in Portugal. Carnivore Damage Prevention News 9: 27-33.

Rigg R. 2001. Livestock Guarding Dogs: Their Current Use Worldwide. IUCN/SSC Canid Specialist Group Occasional Paper no 1. (7 February 2010; www.canids.org/occasionalpapers/livestockguardingdog.pdf)

Shivik JA. 2006. Tools for the edge: What's new for conserving carnivores. BioScience 56: 253-259.

Smith ME, Linnell JDC, Odden J, Swenson JE. 2000. Review of methods to reduce livestock depredation, I: Guardian animals. Acta Agriculturae Scandinavica A: Animal Science 50: 279-290.

Trefethen JB. 1961. Crusade for Wildlife: Highlights in Conservation Progress. Stackpole.

VerCauteren KC, Seward NW, Hirchert DL, Jones ML, Beckerman SF. 2005. Dogs for reducing wildlife damage to organic crops: A case study. Pages 286-293 in Nolte DL, Fagerstone KA, eds. Proceedings of the Eleventh Wildlife Damage Management Conference. National Wildlife Research Center, Animal and Plant Health Inspection Service, US Department of Agriculture.

VerCauteren KC, Lavelle MJ, Hygnstrom SE. 2006. Fences and deer-damage management: A review of designs and efficacy. Wildlife Society Bulletin 34: 191-200.

VerCauteren KC, Lavelle MJ, Phillips GE. 2008. Livestock protection dogs for deterring deer from cattle and feed. Journal of Wildlife Management 72: 1443-1448.

Wagner KK, Nolte DL. 2001. Comparison of active ingredients and delivery systems in deer repellents. Wildlife Society Bulletin 29: 322-330.

Thomas M. Gehring (gehriltm@cmich.edu) is an associate professor of biology in the Department of Biology at Central Michigan University in Mount Pleasant. Kurt C. VerCauteren is a research wildlife biologist at the National Wildlife Research Center, US Department of Agriculture Animal and Plant Health Inspection Service, in Fort Collins, Colorado. Jean-Marc Landry is a research biologist in the Institute for the Promotion and Research on guarding Animals, in Martigny, Switzerland. 